\title{
Sexual and reproductive health activities in HIV programmes: can we monitor progress?
}

\author{
Ryuichi Komatsu, ${ }^{1}$ Donna Lee, ${ }^{1}$ Manjula Lusti-Narasimhan, ${ }^{2}$ Tim Martineau, ${ }^{3}$ \\ Elmar Vinh-Thomas, ${ }^{1}$ Daniel Low Beer, ${ }^{1}$ Rifat Atun ${ }^{1}$
}

\begin{abstract}
${ }^{1}$ The Global Fund to Fight AIDS,
Tuberculosis and Malaria, Geneva, Switzerland

${ }^{2}$ Department of Reproductive Health and Research, WHO,

Geneva, Switzerland

${ }^{3}$ Technical and Country Support, UNAIDS, Geneva, Switzerland
\end{abstract}

\section{Correspondence to}

Dr Ryuichi Komatsu, The Global Fund to Fight AIDS, Tuberculosis and Malaria, Chemin de Blandonnet 8, 1214 Vernier, Geneva, Switzerland; ryuichi. komatsu@theglobalfund.org

Accepted 26 April 2010 Published Online First 14 July 2010

\section{ABSTRACT}

Background Resource allocation and integration of services have been of interest recently to achieve healthrelated Millennium Development Goals. This paper analyses the extent to which countries receiving funding in HIV were able to invest in activities in the area of sexual and reproductive health (SRH).

Methods The authors screened the Global Fund grants data with an aggregate investment of US\$16 billion in 140 countries to identify indicators revealing typical SRH services. The analysis focused on the 'Top Ten' internationally agreed indicators and used international guidelines and frameworks to define services for SRH and opportunities for 'linkage' between HIV and SRH services.

Results As of December 2008, 238 of all HIV grants $(n=252)$ from 133 countries included 1620 service delivery indicators related to $\mathrm{SRH}$. The budgets amounted to US\$9.1 billion with US\$5.9 billion committed and US\$4 billion disbursed. Services included (1) prevention of mother to child transmission for 445000 HIV-positive pregnant women, (2) 5.7 million care and support services, (3) 1.2 billion condoms delivered, (4) 4.4 million episodes of sexually transmitted infections treated, (5) 61 million counselling and testing encounters, and (6) 11.6 million behavioural change communication (BCC) outreach services for people at high risk and 64.5 million BCC activities for the general population, including youth. Information on the linkage and integration of SRH-HIV services was limited.

Conclusion Around 94\% of HIV programmes supported SRH-related activities. However, there is a need to systematically capture data on SRH-HIV service integration to understand the benefits of linking these services.

\section{INTRODUCTION}

To achieve the health-related Millennium Development Goals (MDGs), the Ministerial Meeting to Review International Health Partnership and related initiatives (IHP+) in February 2009 proposed an acceleration of progress to expand partnerships and joint processes of national health and HIV/AIDS planning, including specific diseases, sexual and reproductive health, maternal and child health, and health systems. ${ }^{1}$ In doing so, the global health leaders signalled an end to the unproductive debate that funding for HIV distorted health systems, ${ }^{2}$ or diverted finances away from other areas. ${ }^{3}$ Indeed, the available evidence suggests no such diversion. ${ }^{4-11}$ What is undeniable, however, is the need for more financial resources for low- and middle-income countries if the health MDGs are to be reached. ${ }^{1213}$
The new millennium brought with it a newfound political momentum for increased financial investment in global health beginning with the Group of 8 (G8) meeting in Japan ${ }^{14} 15$ and gathering pace in the United Nations Millennium Declaration with a commitment to the MDGs, followed by the Declaration of Commitment on HIV/AIDS during the UN Special Session on HIV/ AIDS. It was AIDS activism that helped create and sustain this momentum, ${ }^{4} 811$ which led to the creation of an innovative financing mechanism, the Global Fund to Fight AIDS, Tuberculosis and Malaria (Global Fund) in 2002. By the end of 2008, the Global Fund had raised nearly US\$20 billion to effectively fight against the three diseases and attain the international health goals, including the MDGs and universal access to antiretroviral treatment. ${ }^{16-18}$

Strengthening the linkages at the policy level and integration between sexual and reproductive health (SRH) and HIV services can potentially maximise opportunities to reach populations in need, and may be a key to reaching universal access to antiretroviral treatment as well as MDGs 4, 5 and $6 .{ }^{19-22}$ For SRH and HIV, evidence of the impact of their linkage and integration on improving service delivery and increasing uptake is still limited. ${ }^{23-29}$ The Global Fund has emphasised a broad-based approach to fighting the three diseases, by supporting proposals which integrate SRH and maternal and infant health $(\mathrm{MCH})$ components $^{30} 31$ and which support the strengthening of health systems.

This paper analyses the extent to which countries receiving HIV investments were able to request funding for and invest in activities in the area of SRH services.

\section{METHODS}

We used the Global Fund grants data with an aggregate investment of US $\$ 16$ billion in 140 countries to identify and analyse all signed HIV grants $(\mathrm{n}=252)$ representing US\$9.3 billion investment, and grants were screened for indicators that capture SRH-related services. Our analysis covered the period January 2003 to December 2008 and focused on the 'Top Ten' internationally agreed indicators which recipient countries use to report the number of people reached or services provided through grants supported by Global Fund investments. ${ }^{32}$ The process by which countries submit data on selected indicators for analysis by the Global Fund is summarised in box 1 . Data submitted by countries (progress updates) are available on the web (http:// www.theglobalfund.org). 


\section{Box 1 Global Fund grant cycle and reporting}

\section{Grant lifecycle}

- Country submits proposal, assessed by an independent technical review panel, and approved by the Board

- Initial assessment of a recipient

- Grant negotiations and signing

- Grant implementation and monitoring

- Review of progress at the end of second year to determine the renewal of grant

- Grant closure or continuation

Reporting: At the country

- Country selects indicators, sets targets and reporting timelines (quarterly or semi-annually)

- Indicators focus on the most important output categories ("Top Ten") guided by Monitoring \& Evaluation toolkit ${ }^{32}$ (Table 1 shows relevant indicators used in this analysis)

- The grant recipient submits achieved results, verified by regular desk reviews and on-site verifications at least one a year

- Independent data quality audit on random sample of grants, at least once per grant life cycl

Reporting: At Global Fund Secretariat

- Global Fund Secretariat makes progress reports available on the Global Fund website

- Global Fund Secretariat cleans, verifies and codes results

- Data harmonization with partners for specific indicators (e.g. antiretroviral treatment) twice a year

- Release of global results for "Top Ten" twice a year (mid-year and end-year results)

Based on literature search, we used internationally agreed guidelines and frameworks to define services for $\mathrm{SRH}^{33}{ }^{34}$ and linkages between HIV and SRH services ${ }^{19-22} 2535$ (figure 1; table 1). The linkages refer to the policy level. An underlying assumption was that better service integrations reflect better linkages. This was used to analyse all HIV grants to identify those which included SRH-related services, what opportunities for linkages were provided, which indicators were used to describe the performance of these services and whether integration between HIV and SRH services existed.

We grouped countries and territories into generalised, concentrated and low epidemics. ${ }^{37} 38$ This was used to ascertain the level of additional funding provided by the Global Fund in relation to the disease burden. Classification for Estonia, Kosovo, and Sao Tome and Principe were not available; they were included in the 'low' epidemic group. We also analysed the level of investment by geographic regions for HIV and SRH services.

We investigated whether services delivered by programmes with Global Fund investments created opportunities for linking HIV and SRH and provided service integration, and if in practice there was any evidence of current service integrations for four priority areas. ${ }^{20}$ The areas selected were:

\section{Priority linkage 1: learn HIV status and access services}

At the programme level, this HIV-SRH linkage aims to offer voluntary counselling and testing (VCT) services that cater for key populations including young people and pregnant women, and to provide a setting where both VCT and other routine SRH services such as antenatal care, STI treatment and family planning services are readily accessible.

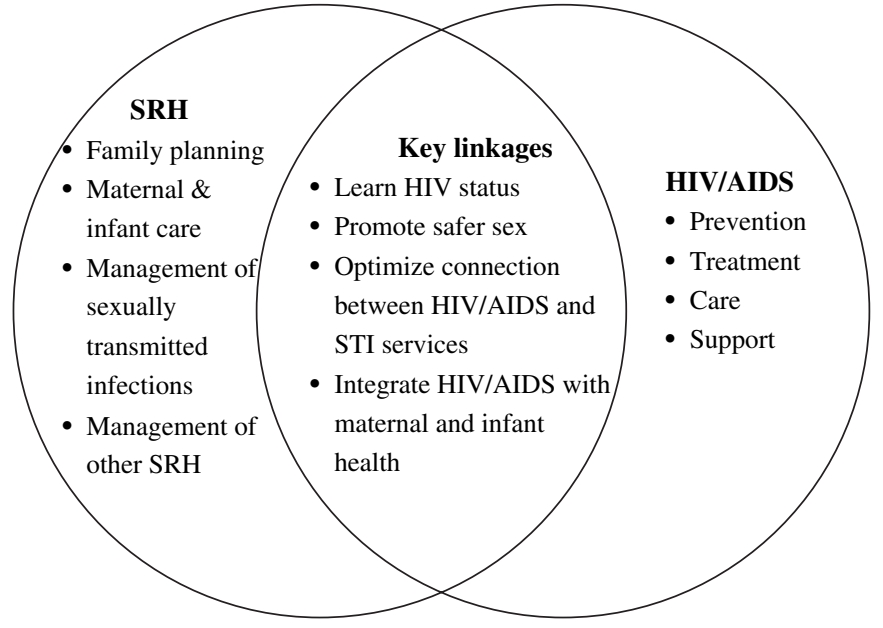

Source (20).

Figure 1 Linking services in sexual and reproductive health \& HIV.

\section{Priority linkage 2: promote safer and healthier sex}

This linkage area aims to reach key populations with different SRH services, including HIV prevention, family planning (eg, condom use, for dual protection), and to raise awareness and communicate on issues such as gender-based violence. ${ }^{20}$ Indicators selected for assessing integration and linkages in this area were condom distribution and BCC outreach services on HIV prevention.

Priority linkage 3: optimise the connection between HIV/AIDS and sexually transmitted infections (STI) services

The idea is to link STI and HIV programmes so that services normally specific to one programme can become an integral part in another. The only 'Top Ten' indicator category selected for assessing this priority linkage was STI treatment.

\section{Priority linkage 4: integrate HIV/AIDS with maternal and infant health}

One of the main elements under this linkage is to ensure the monitoring of all four prongs of the comprehensive strategy for the prevention of HIV infections in women and infants. ${ }^{20} \mathrm{HIV}$ treatment and care, including family planning advice, should be offered to people living with HIV/AIDS (PLWHA) in settings such as antenatal clinics. ${ }^{39}$ Indicators measuring the first prong of the strategy-preventing primary HIV infection among girls and women-were analysed under other priority areas as outlined above (eg, condoms distributed and BCC targeted at women). However, not all aspects of the first prong are covered through available indicators. An indicator to measure the second prong for preventing unintended pregnancy in women living with HIV was not evaluated. Indicators measuring the third prong, a complete course of antiretroviral prophylaxis received by HIV-positive pregnant women for prevention of motherto-child transmission (PMTCT), were examined.

The distribution of service integration and linkage opportunities in these four areas was then mapped by the stage of HIV epidemic grouped into 'generalised' and 'low/concentrated' categories due to the low number of indicators.

We examined how opportunities for the linkages between HIV and SRH services were changed over time, by comparing the level of services in the four linkage areas in grants submitted in Rounds 1 to 5 (between April 2002 and September 2005) and 
Table 1 Analytical frameworks for examining sexual and reproductive health (SRH) indicators in Global Fund-supported HIV programmes

\begin{tabular}{|c|c|c|}
\hline Frameworks SRH care & Frameworks Linkage of SRH-HIV services & $\begin{array}{l}\text { Frameworks SRH-HIV integration and linkages in } \\
\text { Global Fund-supported programmes }\end{array}$ \\
\hline $\begin{array}{l}\text { 1. Global Reproductive Health Strategy }{ }^{33} \\
\text { 2. Recommended interventions for Improving } \\
\text { Maternal and Newborn Health }\end{array}$ & $\begin{array}{l}\text { 1. Framework for Priority Linkages between SRH and } \\
\text { HIV/AIDS } \\
\text { 2. Strengthening linkages for sexual and reproductive } \\
\text { health, HIV and AIDS }\end{array}$ & $\begin{array}{l}\text { 1. Most important output indicators ('Top Ten') } \\
\text { 2. Practical Guidelines for Intensifying HIV Preven- } \\
\text { tion }^{36}\end{array}$ \\
\hline $\begin{array}{l}\text { Five core components } \\
\text { - Antenatal, delivery, postpartum and newborn } \\
\text { care } \\
\text { - Family planning services } \\
\text { - Elimination of unsafe abortion } \\
\text { - Control of sexually transmitted infections } \\
\text { including HIV, reproductive-tract infections, } \\
\text { cervical cancer } \\
\text { - Promoting sexual health }\end{array}$ & $\begin{array}{l}\text { Linkage in four priority areas } \\
\text { - Learn HIV status and access services } \\
\text { - Promote safer and healthier sex } \\
\text { - Optimise the connection between HIV/AIDS and } \\
\text { STI services } \\
\text { - Integrate HIV/AIDS with maternal and infant } \\
\text { health } \\
\text { Linkage by } \\
\text { - Service settings } \\
\text { - Key target populations }\end{array}$ & $\begin{array}{l}\text { Output indicators measuring SRH care (Relevant } \\
\text { 'Top Ten' indicators) } \\
\text { Voluntary counselling and testing } \\
\text { - Condoms delivered } \\
\text { Treatment of sexually transmitted infections } \\
\text { Behaviour change communication services on HIV } \\
\text { prevention (behavioural change communication) } \\
\text { for: } \\
\text { - General population } \\
\text { - Young /pregnant women, young people } \\
\text { - High-risk groups including injecting-drug users, } \\
\text { sex workers and men who have sex with men } \\
\text { HIV-positive pregnant women receiving a complete } \\
\text { course of antiretroviral prophylaxis for prevention of } \\
\text { mother-to-child transmission } \\
\text { Care and support services for people living with } \\
\text { HIV/AIDS }\end{array}$ \\
\hline
\end{tabular}

Rounds 6 and 7 (approved in November 2006 and 2007, respectively). We also attempted to assess health system strengthening issues.

\section{RESULTS}

\section{Overall results of SRH activities}

As of December 2008, 238 out of all 252 HIV grants from 133 countries had included 1620 service delivery indicators (from 'Top Ten') related to SRH. The budget for these 238 grants amounted to US\$9.1 billion with US\$5.9 billion committed and US\$4 billion disbursed.

Countries with generalised epidemics ( $n=40,34 \%$ of total), which accounted for over $70 \%$ of all adults aged 15 and above living with HIV/AIDS, had received the highest proportion of committed funding at US\$3.6 billion (62\% of total committed amount; figure 2). Countries with concentrated epidemics

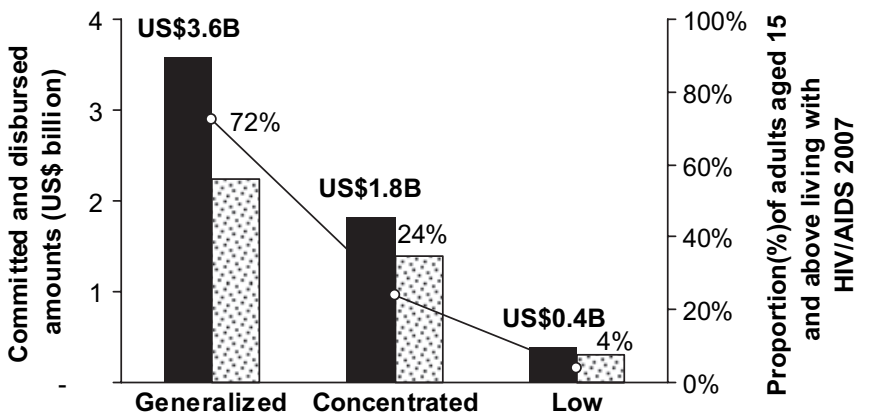

$$
\begin{aligned}
& \text { Committed amounts } \\
& \text { Disbursed amounts } \\
& \text { - Proportion (\%) of adults } 15 \text { and above living with HIVIAIDS } 2007 \text { in } \\
& \text { countries with GF grants providing SRH services (total=28.6 m) }
\end{aligned}
$$

Figure 2 Comparison between funds committed and disbursed in Global Fund (GF) HIV/AIDS grants with sexual and reproductive health (SRH)-related services and proportion of people living with HIV/AIDS aged 15 and above, by stage of HIV epidemic, as of December 2008. (1) Committed and disbursed amounts, and estimated number of PLWHA aged 15 years and above were excluded from multicountry grants. (2) Countries and territories were classified by epidemic stage. ${ }^{42}$ Data on epidemic stage were not available for Estonia, Kosovo, Sao Tome and Principe, and these were grouped under 'low.' received a commitment of US\$1.8 billion (31\%) and lowepidemic countries US\$0.4 billion (7\%)

Table 2 shows the number of people reached and services delivered for SRH as measured by the SRH output indicators examined. These included (1) a complete course of antiretroviral prophylaxis for prevention of mother to child transmission (PMTCT) for 445000 HIV-positive pregnant women, (2) 5.7 million care and support services for PLWHA, (3) 1.2 billion condoms delivered, (4) 4.4 million episodes of STI treated, (5) 61 million VCT encounters provided and (6) 11.6 million behavioural change communication (BCC) outreach services for people at high risk and 64.5 million BCC services for the general population, including young people. Regional variances were large.

The emphasis given to the range of services in countries at different stages of HIV epidemic varied (figure 3 ). The 38 countries with generalised epidemics emphasised PMTCT, care and support for PLWHA and condom distribution, accounting for $86 \%$ of the 445000 PMTCT interventions, $67 \%$ of 5.7 million care and support services for PLWHA), and $64 \%$ of 1.2 billion condoms distributed. The 40 countries with a concentrated HIV epidemic, emphasised STI treatment, VCT and BCC outreach services targeting high-risk groups; accounting for $55 \%$ of 4.4 million STI cases treated, $51 \%$ of 61 million VCT encounters and $43 \%$ of 11.6 million BCC outreach services targeting high-risk groups. The 33 countries with low-level HIV epidemics emphasised BCC HIV prevention targeting the general population accounting for $37 \%$ of 64.5 million outreach services provided, though the level of the services did not vary greatly among the different epidemic scenarios.

\section{Linking SRH and HIV in the four priority areas by setting and key populations}

Priority linkage 1: learn HIV status and access services

Of the 285 VCT service indicators examined, 32\% specified target populations especially young/pregnant women, and high-risk groups, while $10 \%$ of the indicators demonstrated evidence for integrated SRH-HIV services, such as VCT conducted in antenatal care settings or in sexual and reproductive health clinics, or the provision of STI treatment together with VCT services, or women in antenatal clinics tested for HIV and screened for other STIs like syphilis. However, $58 \%$ of VCT indicators examined did 
Table 2 Results of services delivered to people, as measured by sexual and reproductive health output indicators from Global Fund-supported HIV programmes as of December $2008^{*} \S$

\begin{tabular}{|c|c|c|c|c|c|c|c|}
\hline Region $†$ & $\begin{array}{l}\text { Prevention of } \\
\text { mother-to-child } \\
\text { transmission } \ddagger\end{array}$ & $\begin{array}{l}\text { Care and support } \\
\text { services for people } \\
\text { living } \\
\text { with HIV/AIDS }\end{array}$ & $\begin{array}{l}\text { Condoms } \\
\text { distributed }\end{array}$ & $\begin{array}{l}\text { Treatment for } \\
\text { STIs }\end{array}$ & $\begin{array}{l}\text { Voluntary } \\
\text { counselling } \\
\text { and testing } \\
\text { provided }\end{array}$ & $\begin{array}{l}\text { Behavioural change } \\
\text { communication } \\
\text { services for } \\
\text { high-risk individuals }\end{array}$ & $\begin{array}{l}\text { Behavioural } \\
\text { change } \\
\text { communication } \\
\text { services for } \\
\text { young } \\
\text { people, general } \\
\text { population }\end{array}$ \\
\hline Eastern Africa & 121000 & 1.3 million & 450 million & 280000 & 17 million & 5700 & 8.6 million \\
\hline Southern Africa & 211000 & 1.7 million & 202 million & 250000 & 8.5 million & 24000 & 8.5 million \\
\hline West \& Central Africa & 46000 & 360000 & 79 million & 420000 & 2.6 million & 2.3 million & 2.8 million \\
\hline East Asia \& Pacific & 5000 & 400000 & 173 million & 990000 & 2.3 million & 940000 & 11.0 million \\
\hline South Asia & 28000 & 1.1 million & 1.1 million & 90000 & 13 million & 700000 & 11.8 million \\
\hline $\begin{array}{l}\text { Eastern Europe \& } \\
\text { Central Asia }\end{array}$ & 18000 & 180000 & 75 million & 120000 & 12 million & 3.1 million & 7.9 million \\
\hline $\begin{array}{l}\text { Latin America \& the } \\
\text { Caribbean }\end{array}$ & 12000 & 650000 & 200 million & 1.46 million & 5.3 million & 2.0 million & 11.2 million \\
\hline $\begin{array}{l}\text { Middle East \& } \\
\text { North Africa }\end{array}$ & 4000 & 37000 & 38 million & 770000 & 320000 & 2.6 million & 3.2 million \\
\hline All regions & 445000 & 5.7 million & 1.2 billion & 4.4 million & 61.0 million & 11.7 million & 64.9 million \\
\hline
\end{tabular}

*Figures are rounded.

†Regions defined according to Global Fund regions, refer to http://www.theglobalfund.org/en/.

$\ddagger$ HIV-positive pregnant women receiving antiretroviral prophylaxis for prevention of mother-to-child transmission.

§For complete indicator descriptions agreed with international partners, please refer to the Monitoring and Evaluation Toolkit 2009 ${ }^{32}$ available from http://www.theglobalfund.org/en/.

not specify key populations targeted, or provided information on the settings in which services were provided (data not shown).

\section{Priority linkage 2: promote safer and healthier sex}

A total of 757 indicators were examined in relation to this priority linkage area. Around $75 \%$ of the indicators specified targeted populations, namely high-risk groups and young people/women, but only $4 \%$ of indicators specified integrating different SRH and HIV services within a particular geographic setting: for example, distributing condoms at settings offering VCT or STI treatment, offering HIV education, counselling and referral services when reaching special groups, and offering HIV and STI prevention and sensitisation sessions when sex workers were reached. About $20 \%$ of the indicators did not specify the target population or the settings where services were offered.

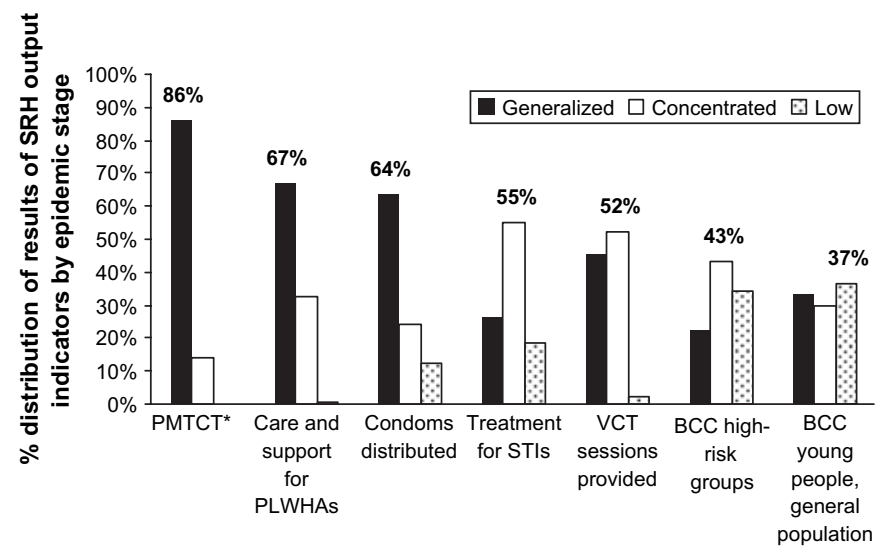

GF Top Ten indicator categories measuring SRH care

Figure 3 Distribution of results of Global Fund (GF) sexual and reproductive health ( $\mathrm{SRH}$ ) output indicators by epidemic stage, as of December 2008. (1) Countries and territories were classified by epidemic stage. ${ }^{42}$ Data on epidemic stage were not available for Estonia, Kosovo, Sao Tome and Principe, and these were grouped under 'low.' *HIV-positive pregnant women receiving antiretroviral prophylaxis for prevention of mother-to-child transmission (PMTCT). BCC, behaviour change communication; PLWHA, people living with HIV/AIDS; VCT, voluntary counselling and testing.
Priority linkage 3: optimise linkages between HIV/AIDS and STI services

The findings in this area were disappointing, as 73\% of STI indicators analysed did not specify target populations or the setting for service provision. Furthermore, while $20 \%$ of the 120 indicators examined in this area specifically mentioned target groups to be served, $7 \%$ specified integration of STI services with HIV services, for example, providing STI treatment in AIDS centres, screening and treatment for women during antenatal care, or for screening and treating injecting drug users (IDUs) in youth-friendly centres.

Priority linkage 4: integrate HIV/AIDS with maternal and infant health Of the 121 indicators used to monitor services for HIV-positive pregnant women, only three described the setting where these services were provided. Similarly, of the 310 indicators for care and support services for PLWHA, only $7 \%$ explicitly mentioned services targeted at HIV-positive women.

In both the 'generalised' and 'low/concentrated' epidemic settings, SRH indicators showed the highest percentage of services in the priority linkage area 'promote safer and healthier sex' $(74 \%$ and $79 \%$, respectively, of all integration indicators). The generalised epidemic countries showed a higher proportion of integrated indicators than countries in the low/concentrated category in two of the priority areas: 'learn HIV status and access services' (21\% vs $14 \%$ ) and 'integrate HIV/AIDS with maternal and infant health' (4\% vs $2 \%$ ). By contrast, low/ concentrated epidemic countries showed a higher proportion of indicators in the priority areas: 'optimise connection between HIV/AIDS and STI services' (5\% vs $1 \%$; data not shown).

Comparison of SRH indicators used in grants for Rounds $1-5$ and Rounds 6-7 (total $1593 \mathrm{SRH}$ indicators examined; 789 indicators showing linkage opportunities) showed that the proportion demonstrating SRH-HIV linkage opportunities increased for two priority areas, namely 'learn HIV status and access services' (40\% to 51\%) and 'optimise connection between HIV/AIDS and STI' (26\% to 33\%). In contrast, the proportion of $\mathrm{SRH}$ indicators showing integration with $\mathrm{MCH}$ declined ( $6 \%$ to 4\%; data not shown).

Health system-related indicators could also provide an insight into service linkages. We examined 120 indicators in 90 of the 
238 HIV grants used to monitor investments for infrastructure or services supporting the provision of PMTCT, VCT and STI management. The infrastructure typically referred to primary healthcare units, health centres and integrated clinics that offered packages of PMTCT services. In addition, around 60 grants that had service indicators relating to training of human resources specifically mentioned staff training for VCT, PMTCT and SRH. Furthermore, over 40 grants had indicators measuring the training of health and community workers to conduct outreach to high-risk groups such as MSM, sex workers and IDUs.

\section{DISCUSSION}

Here, we present an initial analysis of sexual and reproductive health activities in HIV grants supported by the Global Fund. Our analysis demonstrates that around 94\% of all $252 \mathrm{HIV}$ grants supported by the Global Fund in 133 countries included some elements of SRH. Specifically, those grants had indicators covering any one of six SRH indicator categories listed in table 1. The proportions of the grants that included indicators from two and three categories were $88 \%$ and $72 \%$, respectively (results not shown). The large majority of grants do cover SRH-related activities.

Our analysis of the indicators formulated for the SRH services shows opportunities for linkage of SRH-HIV services for key populations but gives limited information on how these linkages are realised and services are integrated in different service settings. In the priority area 'learn HIV and access services,' around $10 \%$ of VCT indicators showed integration of different services by setting-for example, VCT or STI treatment in antenatal care settings. Data providing evidence of integration for the other three priority areas were lacking. Countries with generalised epidemics appeared to have a higher proportion of integration in the area 'learn HIV and access services,' consistent with international recommendations. ${ }^{20} 36$

In our attempt to enumerate SRH-HIV indicators in Global Fund grants, we encountered several limitations. The lack of $\mathrm{SRH}$-specific indicators hampered the identification of service integration and missed opportunities for linkages. An example is the lack of an indicator to measure unmet need for family planning among women living with HIV (Prong 2 of the global PMTCT strategy). Indicators are extracted from proposals to monitor overall progress and do not necessarily contain the same level of detail as in the original grant proposal. ${ }^{30}$ While the finding that $94 \%$ of HIV grants included elements of SRH care may sound obvious, as the major mode of HIV transmission is sexual, it is difficult to measure linkage and integration with the current indicators. In addition, the concept of integration and linkage does not have internationally agreed standard indicators and definitions. ${ }^{1920}$ The Advocacy Summit on the integration of sexual and reproductive health provided guidance on integrating SRH-HIV activities in Global Fund-supported grants ${ }^{40}$; subsequently there appears to have been an increase in the number of SRH-HIV output indicators showing integration. Our study points to a need for clear guidance on indicators that better capture integrations between SRH and HIV services and linkages and their implementation. The Global Fund has been proactively harmonising M\&E indicators with partners.

The SRH and HIV activities examined in the study suggest the presence of a balanced portfolio of services covering prevention, treatment and care. The services provided through the Global Fund-supported programmes were generally in line with internationally recommended practices. ${ }^{36}$

\section{What is already known on this subject}

Strengthening the linkages at the policy level and integration between sexual and reproductive health (SRH) and HIV services can potentially maximise opportunities to reach populations in need, and be a key to reaching universal access to antiretroviral treatment as well as MDGs 4, 5 and 6.

\section{What this study adds}

This paper analyses the extent to which countries receiving HIV investments were able to request funding for and invest in activities in the area of SRH services. Around $94 \%$ of HIV programmes supported SRH-related activities.

\section{Policy implications}

There is a need to systematically capture data on SRH-HIV service integration to understand the benefits of linking these services.

PMTCT, care and support for PLWHA, and condom distribution were the predominant service categories for generalised HIV epidemic countries. This is in line with need, as in generalised epidemics more women of childbearing age are HIVpositive, and hence PMTCT services are a critically important intervention for this group. Furthermore, care and support services are needed to cater for the needs of the large number of PLWHA. Since the epidemic is generalised, prevention efforts need to target the entire sexually active population.

In the concentrated HIV epidemic countries, the largest share of SRH activities in the Global Fund-supported HIV grants were for STI treatment, VCT and BCC for HIV prevention in highrisk groups. The preponderance of these activities reflects the need in these contexts to focus on critical prevention activities to contain the spread of the epidemic into 'bridge populations.'

In countries with low HIV epidemics, BCC outreach services for HIV prevention targeting the general population, especially young people, prevailed. This was followed by BCC outreach to high-risk groups. The findings suggest that countries with a low level of HIV focus their prevention activities not only on the general population but also on high-risk population groups, which is more important.

As recommended by a number of internationally developed frameworks and guidelines, ${ }^{20} 25 \quad 3941 \quad 42$ linking SRH-HIV policies and integrating services has many potential benefits, including improved access and uptake of both SRH-HIV services, reduction of HIV/AIDS stigma and improved SRH service coverage of marginalised groups. However, not all SRH-HIV services are immediately suited for integration and linkage, and the opportunity for linkage will also be determined by the nature of the epidemic, health system characteristics, and political and cultural contexts of countries. ${ }^{36} 3841$

In conclusion, HIV programmes, at least in most Global Fundsupported programmes, include SRH services. There is evidence of opportunities for service linkage for key populations especially 
those most at risk, but the evidence on the extent of service integration in different settings, and how linkages affect service quality and coverage, is absent. There is a need to systematically capture data on SRH-HIV policy linkages and service integrations augmented by case studies to understand the benefits of linking these services to ensure scarce resources are applied to areas and solutions that produce the desired results.

\section{Competing interests None.}

Contributors RK and DL coordinated and designed the study and interpreted findings. $\mathrm{DL}$ also carried out the analysis. ML-N, TM, and EV-T contributed to interpretation. DLB and RA provided overall guidance and interpretation. All authors contributed to the writing of the paper. RK and DL accept full responsibility for the work and the conduct of the study, had access to the data and controlled the decision to publish.

Provenance and peer review Not commissioned; externally peer reviewed.

\section{REFERENCES}

1. International Health Partnership and related initiatives. IHP + ministerial review communiqué, 5 Feb 2009.http://www.internationalhealthpartnership.net/CMS files/ documents/ministerial review meeting commu EN.pdf (accessed Jun 2010).

2. England R. Are we spending too much on HIV? BMJ 2007;334:344.

3. Shiffman J. Has donor prioritization of HIV/AIDS displaced aid for other health issues? Health Policy Plan 2008;23:95-100.

4. Ooms G. Shifting paradigms: how the fight for 'universal access to AIDS treatment and prevention' supports achieving 'comprehensive primary health care for all.' Global Health 2008;4:11.

5. Yu D, Souteyrand Y, Banda MA, et al. Investment in HIV/AIDS programs: does it help strengthen health systems in developing countries. Global Health 2008;4:8.

6. Reich MR, Takemi K, Roberts MJ, et al. Global action on health systems: a proposal for the Toyako G8 summit. Lancet 2008;371:865-9.

7. Bhattacharya $\mathbf{S}$. The local bases of global public health: complexities and opportunities. Bull World Health Organ 2008;86:163.

8. Piot $\mathbf{P}$, Kazatchkine $\mathrm{M}$, Dybul $\mathrm{M}$, et al. AIDS: lessons learnt and myths dispelled. Lancet 2009;374:260-3.

9. Uplekar M, Raviglione M. The 'vertical-horizontal' debates: time for the pendulum to rest (in peace)? Bull World Health Organ 2007:85:413-14.

10. Reich MR, Takemi K. G8 and strengthening of health systems: follow-up to the Toyako summit. Lancet 2009;373:508-15.

11. de Lay $\mathbf{P}$, Greener $\mathrm{R}$, Izazola JA. Are we spending too much on HIV? BM 2007; 334:345

12. High Level Taskforce on Innovative International Financing for Health Systems Working Group 1. Constraints to Scaling-up and Costs: First Report to Taskforce, 2009. http:// www.internationalhealthpartnership.net//CMS_files/documents/working_group_1_ report: constraints to scaling up and costs EN.pdf (accessed Jun 2010).

13. High Level Taskforce on Innovative International Financing for Health Systems Working Group 2. Raising and Channeling Funds: Progress Report to Taskforce, 2009. http://www. internationalhealthpartnership.net//CMS files/documents/working group 2 report: raising and channeling funds EN.pdf (accessed Jun 2010).

14. Watts J. G8 countries set priorities for infectious diseases but fail to make progress on debt relief. Bull World Health Organ 2000:78:1168.

15. Watts J. Targets now set by G8 countries to reduce 'diseases of poverty'. Lancet 2000:356:408

16. Komatsu R, Low-Beer D, Schwartlander B. Global Fund-supported programmes contribution to international targets and the Millennium Development Goals: an initial analysis. Bull World Health Organ 2007:85:805-11.

17. Low-Beer D, Afkhami H, Komatsu R, et al. Making performance-based funding work for health. PLoS Med 2007;4:1308-11.

18. Komatsu R, Korenromp EL, Low-Beer D, et al. Lives saved by Global Fund-supported HIV/AIDS, tuberculosis and malaria programs: estimation approach and results between 2003 and end-2007. BMC Infect Dis 2010;10:109.
19. WHO, UNFPA, IPPF, et al. Sexual \& Reproductive Health and HIV: Linkages: Evidence Review and Recommendations. Geneva: WHO, 2008.

20. WHO, UNFPA, UNAIDS, IPPF. Sexual and Reproductive Health \& HIVIAIDS. A Framework for Priority Linkages. Geneva, Switzerland: WHO, 2005.

21. WHO, UNFPA, UNAIDS, IPPF. Linking Sexual and Reproductive Health and HIV/ AIDS, Gateways to Integration: A Case Study from Haiti. Geneva: WHO, 2008.

22. WHO, UNFPA, UNAIDS, IPPF. Linking Sexual and Reproductive Health and HIV/ AIDS, Gateways to Integration: A Case Study from Kenya. Geneva: WHO, 2008.

23. Askew I, Berer M. The contribution of sexual and reproductive health services to the fight against HIV/AIDS: a review. Reprod Health Matters 2003;11:51-73.

24. Druce N, Nolan A. Seizing the big missed opportunity: linking HIV and maternity care services in sub-Saharan Africa. Reprod Health Matters 2007;15:190-201.

25. Druce N, Dickinson C, Attawell K, et al. Strengthening Linkages for Sexual and Reproductive Health, HIV and AIDS: Progress, Barriers and Opportunities. London: DFID Health Resource Centre, 2006.

26. Briggs C, Garner P. Strategies for integrating primary health services in middle- and low income countries at the point of delivery. Cochrane Database Syst Rev 2006:(2):CD003318

27. Atun RA, de Jongh T, Secci F, et al. Integration of targeted health interventions into health systems: A conceptual framework for analysis. Health Policy Plan 2009;25:104-11.

28. Atun RA, de Jongh $T$, Secci $F$, et al. A systematic review of the evidence on integration of targeted health interventions into health systems. Health Policy Plan 2010;25:1-14

29. Atun RA, Bennett S, Duran A. When do vertical (stand-alone) programmes have a place in health systems? Policy Brief. Copenhagen: WHO Regional Office for Europe, 2008.

30. Lusti-Narasimhan M, Collin C, Mbizvo M. Sexual and reproductive health in HIVrelated proposals supported by the Global Fund to Fight AIDS, Tuberculosis and Malaria. Bull World Health Organ 2009:87:816-23.

31. Safreed-Harmon K, Daly M. Review of Country Coordinating Mechanism Proposals with SRH-HIVIAIDS Integration Submitted to the Global Fund Round 8, 2008. http:// whqlibdoc.who.int/hq/2005/WHO HIV 2005.05 eng.pdf (accessed Jun 2010).

32. Global Fund to fight AIDS Tuberculosis and Malaria. Monitoring and Evaluation Toolkit HIV, Tuberculosis and Malaria and Health Systems Strengthening, 3rd edn, Globa Fund to fight AIDS Tuberculosis and Malaria. Geneva: The Global Fund, 2009. http:// www.interactworldwide.org/objs/1219748059-rd8_srh_hiv_shadow_report_final.pdf (accessed Jun 2010).

33. WHO. Accelerating Progress Towards the Attainment of International Reproductive Health Goals. a Framework for Implementing the WHO Global Reproductive Health Strategy. Geneva: WHO, 2006.

34. WHO. WHO Recommended Interventions for Improving Maternal and Newborn Health. Geneva: WHO, 2007

35. IPPF, UNFPA, WHO, et al. Rapid Assessment Tool for Sexual \& Reproductive Health and HIV Linkages: A Generic Guide, 2008.

36. UNAIDS. Practical Guidelines for Intensifying HIV Prevention: Towards Universal Access. Geneva: UNAIDS, 2007.

37. WHO, UNAIDS, Unicef. Towards Universal Access: Scaling Up Priority HIVIAIDS Interventions in the Health Sector: Progress Report 2008. Geneva: WHO, 2008.

38. UNAIDS. Report on the Global HIVIAIDS Epidemic 2008. Geneva: UNAIDS, 2008.

39. WHO. HIV Technical Briefs. Strengthening Linkages Between Family Planning and HIV: Reproductive Choices and Family Planning for People Living with HIV. Geneva: WHO, 2007.

40. Allison C. Report of the Advocacy Summit on the Global Fund Round 7: Integration of Sexual and Reproductive Health Into the HIV and Malaria Component Proposals. London: HLSP, 2006

41. WHO, HIV. Technical briefs. strengthening linkages between sexual and reproductive health and HIV. Geneva: WHO, 2007.

42. Dickinson C. Integration Between Sexual and Reproductive Health and HIV and AIDS and Malaria: Opportunities and Strategic Options for the Global Fund to Fight AIDS, Tuberculosis and Malaria. Discussion piece. London: HLSP, 2006:47. 